\title{
Optociliary veins and central retinal vein occlusion
}

\author{
Giuseppe Giuffrè, Carlo Palumbo, Gaetano Randazzo-Papa
}

\begin{abstract}
In a follow up of 94 patients with central retinal vein occlusion (CRVO) whose onset had taken place less than 1 year earlier, optociliary veins (OCVs) were found in $7.4 \%$ at first examination. Among the 79 eyes in which the fundus of the eye was very visible after a follow up of more than 1 year OCVs were found in $30.4 \%$, showing a late development of OCVs in many 'cases of CRVO. No difference was found in the occurrence of OCVs between non-ischaemic and ischaemic forms of CRVO. The visual acuity of the eyes with CRVO that developed OCVs was not significantly different from the visual acuity of the eyes without OCVs. Thus, the presence of OCVs in CRVO does not seem to be associated with better visual prognosis. (Brf Ophthalmol 1993; 77: 774-777)
\end{abstract}

Optociliary veins (OCVs) are vessels located on the optic disc shunting the retinal to the choroidal venous circulation. They are seen when an impairment to the outflow of blood in the retrobulbar tract of the central retinal vein exists; thus OCVs are alternative pathways for the drainage of retinal blood. ${ }^{1}$ It is debatable whether OCVs are collaterals that form when the venous outflow is obstructed ${ }^{2}$ or whether they are present normally, but enlarge when the drainage is impaired. ${ }^{34}$ This latter hypothesis would seem the more probable.

OCVs are found in ocular diseases like central retinal vein occlusion (CRVO) or hemicentral retinal vein occlusion, ${ }^{5-8}$ glaucoma, ${ }^{910}$ optic nerve meningioma, ${ }^{21-13}$ and papilloedema. ${ }^{15}$ Most OCVs are seen in eyes with previous CRVO. ${ }^{16} 17$

Not much is known of the clinical importance of OCVs in CRVO. It is uncertain whether their development bears any relation to final visual acuity or whether OCVs are more frequent in the non-ischaemic or ischaemic types of CRVO; and it is not clear when such vessels develop.

We have studied and followed up a large number of eyes affected with CRVO with the purpose of showing the occurrence of OCVs and of ascertaining their clinical significance.

\section{Patients and methods}

Ninety four subjects with CRVO were followed up for more than 1 year. All these subjects were seen at the fluorescein angiographic service of the University Eye Clinic of Palermo. The first examination was made within 1 year from the onset of the CRVO.

At first visit as well as at follow up examinations the corrected visual acuity and the condition of the anterior as well as the posterior segment of the eye was evaluated. In addition to fluorescein angiography, fundus colour and red free photographs were taken.
The diagnosis of CRVO was made on the basis of sudden blurred vision in a subject presenting with unilateral dilatation of the retinal venous tree accompanied by multiple retinal haemorrhages.

CRVOs were classified as non-ischaemic and ischaemic types. The presence of retinal ischaemia was evaluated by fluorescein angiography, quantifying the extent of the retinal area lacking blood perfusion. Five standard fluorescein angiograms were evaluated: one included the posterior pole and the optic disc; the others included four pictures of the retinal midperiphery placed nasally, temporally, superiorly, and inferiorly to the posterior pole. When such ischaemic areas were absent or involved less than $30 \%$ of the photographed retinal surface (posterior pole and mid periphery), the CRVO was classified as non-ischaemic; when the ischaemic areas involved more than $30 \%$ of the retinal surface the CRVO was classified as ischaemic. In some cases in which the CRVO was of recent onset it was impossible to classify the form as non-ischaemic or ischaemic since the number of haemorrhages did not permit observation of the ischaemic areas. These forms were classified as not determined.

The filling time of the central retinal vein was also evaluated in fluorescein angiography as the lapse of time between injection of the dye and the moment in which the laminar flow could be observed in the portion of the central retinal vein near the optic disc.

OCVs were defined as large venous vessels, located near the edge of the optic disc, shunting retinal vessels on the disc to deep choroidal vessels of the peripapillary region. The presence of OCVs was evaluated in colour and red free photographs, since their identification is easier in these photographs rather than in fluorescein angiography. Slightly dilated capillaries located on the optic disc which could not be classified with certainty as OCVs were not considered.

\section{Results}

The average age of the 94 patients with CRVO was 59 (SD 13) years; there were 51 men and 43 women. There were 51 non-ischaemic forms, 40 ischaemic forms, and three not determined. We examined 55 patients within 1 month of onset of the CRVO, 17 patients between 1 and 3 months, and the remaining 22 patients between 3 months and 1 year after the development of the CRVO.

During the first ophthalmic examination only seven out of the 94 patients showed OCVs $(7 \cdot 4 \%)$. The OCVs were seen as early as 20 days or as late as $\mathbf{3 0 0}$ days after the CRVO (Table 1). In the two cases in which the appearance of OCVs was precocious the visual acuity was normal either at first examination or at follow up after more than 1 year. However, when the OCVs 
Table 1 Eyes with CRVO in which OCVs were visible within 1 year after the onset of the disease

\begin{tabular}{lllll}
\hline $\begin{array}{l}\text { Time between CRVO and } \\
\text { observation of OCVs (days) }\end{array}$ & Age & $\begin{array}{l}\text { Type of } \\
\text { CRVO }\end{array}$ & $\begin{array}{l}\text { Visual acuity at first } \\
\text { examination }\end{array}$ & $\begin{array}{l}\text { Visual acuity } \\
\text { at follow up }\end{array}$ \\
\hline 20 & 54 & NI & $1 \cdot 0$ & $1 \cdot 0$ \\
30 & 17 & NI & $1 \cdot 0$ & $1 \cdot 0$ \\
60 & 65 & NI & $0 \cdot 3$ & $0 \cdot 1$ \\
90 & 66 & I & $0 \cdot 01$ & LP \\
200 & 53 & NI & $0 \cdot 01$ & $0 \cdot 1$ \\
280 & 69 & NI & $0 \cdot 3$ & $0 \cdot 01$ \\
340 & 59 & I & 0.05 & $0 \cdot 01$ \\
\hline
\end{tabular}

$N I=$ non-ischaemic $;=$ ischaemic .

were seen a long time after the occurrence of CRVO, the visual acuity was low at first examination as well as at follow up.

At re-examination some cases of CRVO changed to more serious forms - namely, some non-ischaemic CRVOs developed into ischaemic forms. In 15 cases it was impossible to evaluate the ocular fundus at follow up because of cataract or some other disease of the ocular media. Among the remaining 79 eyes 45 had nonischaemic CRVO and 34 ischaemic CRVO. Twenty four out of the $79(30 \cdot 4 \%)$ had OCVs. In seven of these 24 eyes the OCVs were also present at the first examination. The OCVs showed slight differences at follow up compared with the first examination: in two eyes they were reduced in diameter (Fig 1), but no eye presenting OCVs at the initial examination was free from the condition at follow up.

There were no differences relating to age and occurrence of OCVs. At first examination four out of 45 patients aged less than 60 had OCVs compared with three out of 49 patients aged 60 or more. At follow up 11 out of the 39 younger patients in which it was possible to examine the fundus of the eye developed OCVs and 13 out of the 40 older patients had OCVs.

When the follow up lasted between 1 and 2 years $26 \cdot 3 \%$ of CRVOs showed OCVs and this figure had not changed significantly for longer follow up periods, reaching $32 \cdot 2 \%$ for follow up of more than 6 years. Non-ischaemic CRVOs had OCVs more frequently than ischaemic ones, but the difference was not statistically significant $\left(\chi^{2}=0.817 ; p=0.266\right)$ (Table 2).

The filling time of the central retinal vein, as determined by fluorescein angiography done at the onset of CRVO, was $21 \cdot 5(5 \cdot 2)$ seconds in those eyes presenting OCVs at follow up and 19 $(4 \cdot 7)$ seconds in eyes showing no OCV at follow up; the difference was not statistically significant $(t=1 \cdot 259 ; \mathrm{p}=0 \cdot 213)$.

Within the ischaemic CRVOs four out of 22 eyes in which panretinal argon laser photocoagulation was performed developed OCVs, as well as four out of 12 eyes in which laser therapy was not used $\left(\chi^{2}=0.328 ; p=0.567\right.$, not significant).

Eight out of 94 patients with CRVO developed neovascular glaucoma. Three of them had been treated with panretinal argon laser photocoagulation. No evidence of OCV was observed at the first examination in any of these cases. At the time of re-examination, in six cases the fundus was not visible or not sufficiently visible to ascertain the presence of OCVs. In the two remaining cases OCVs were not observed.

As regards the improvement (or worsening) of visual acuity, no statistically significant difference was found between CRVOs that developed OCVs and CRVOs that did not develop them $\left(\chi^{2}=0.538: p=0.764\right)$ (Table 3).

Among the 24 eyes with OCVs at follow up, four showed an improvement of visual acuity, four had no changes, and 16 presented a worsening.

\section{Discussion}

The occurrence of OCVs in CRVO is the subject of several studies. Masuyama et $^{\mathrm{al}} \mathrm{l}^{18}$ in a retrospective study found OCVs in $7 \cdot 4 \%$ of 190 cases of CRVO. However, this number is not very helpful because the time of onset of CRVO is not specified. In addition, eyes with hemicentral retinal vein occlusion were included: in these cases the haemodynamics at the level of the prelaminar portion of the retinal vein is different from that in CRVO, since the blood can be shunted towards the second, pervious hemicentral retinal vein through retinal venovenous anastomoses. ${ }^{19}$ De Crecchio et al, ${ }^{8}$ in a prospective study, found OCVs in $15 \%$ of 146 eyes with CRVO; among patients followed up for more than 1 year OCVs were observed in $28 \%$.

We were able to obtain initial and follow up
Figure 1 (A) Fifteen days after the onset of central retinal vein occlusion no optociliary veins are visible. (B) Eleven months later optociliary veins are found in the superonasal and inferotemporal aspects of the optic disc. (C) After three and $a$ half years only $a$ reduced optociliary vein is present in the nasal half of the optic disc.

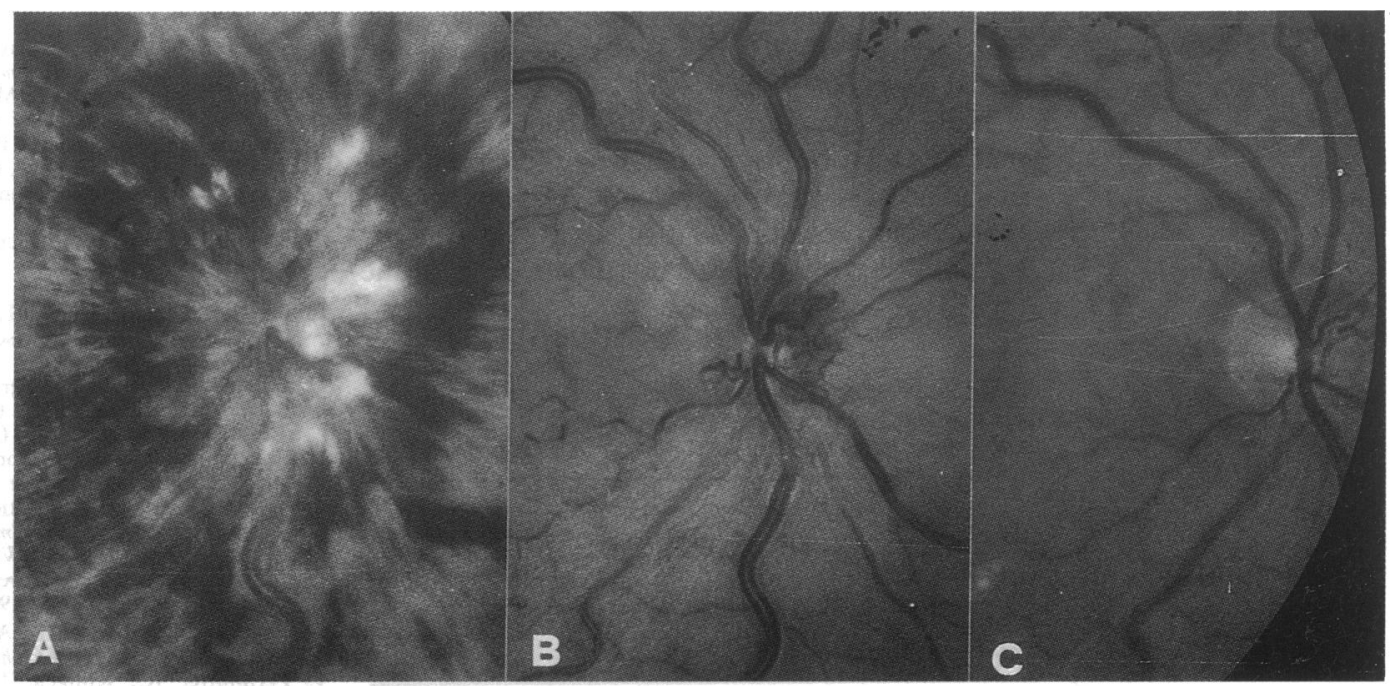


Table 2 Occurrence of optociliary veins in eyes with central retinal vein occlusion after a follow up period of 1 year or more

\begin{tabular}{lllll}
\hline Type & $\begin{array}{l}1-2 \text { years } \\
\text { after onset }\end{array}$ & $\begin{array}{l}\text { 2-6 years } \\
\text { after onset }\end{array}$ & $\begin{array}{l}\text { 6-10 years } \\
\text { after onset }\end{array}$ & Total \\
\hline Total & $5 / 19(26 \cdot 3 \%)$ & $9 / 29(31 \%)$ & $10 / 31(32 \cdot 3 \%)$ & $24 / 79(30 \cdot 4 \%)$ \\
Non-ischaemic & $3 / 10(30 \%)$ & $5 / 13(38 \cdot 5 \%)$ & $8 / 22(36 \cdot 4 \%)$ & $16 / 45(35 \cdot 6 \%)$ \\
Ischaemic & $2 / 9(22 \cdot 2 \%)$ & $4 / 16(25 \%)$ & $2 / 9(22 \cdot 2 \%)$ & $8 / 34(23 \cdot 5 \%)$ \\
\hline
\end{tabular}

data for more than 1 year in 94 patients with CRVO. When the onset of CRVO was not more than 1 year earlier, $7 \cdot 4 \%$ of the eyes developed OCVs. The finding of OCVs immediately after the onset of CRVO was extremely rare, but in these few cases the OCVs seem to be related to a better prognosis, even if the small number of such cases does not permit any conclusion. It is possible that in some other cases the OCVs are present at a very early stage, but they are unrecognisable because of their small dimensions and the masking effect of disc haemorrhages.

In the absence of further signs of CRVO, the presence of OCVs permits the diagnosis of previous CRVO. ${ }^{20}$ In this respect OCVs, which in most cases remain indefinitely after the CRVO, are of clinical importance. In some studies it was found that the presence of OCVs in CRVO was accompanied by a better visual prognosis. Priluck et $a l^{7}$ in a study of CRVO in young people found that the final visual acuity of the subjects who had developed OCVs was better than that of the remaining subjects lacking OCVs. Blinder $e t a l,{ }^{21}$ in a group of subjects of 45 years or older with CRVO, showed that the development of OCVs was associated with a stable or improved visual acuity, while their absence was generally associated with worsening of the visual acuity; however, the number of subjects involved in these studies was small, 42 and 32 subjects respectively.

Our study, performed on 79 cases of CRVO with a minimum follow up period of 1 year, did not show similar results. No statistically significant difference was found between subjects with OCVs and without OCVs as regards the visual acuity. In addition, most subjects with CRVO and OCVs show a worsening of vịsual acuity as generally occurs in subjects with CRVO; the only exception was the case in which the OCV developed early on. The small number of eyes in which we demonstrated OCVs soon after CRVO can in no way be considered as proof that the early development of OCVs is associated with a good visual prognosis.

Final visual acuity in CRVO is determined by many factors, but particularly by the presence of macular ischaemia or oedema (excluding eyes that develop neovascular glaucoma). Since OCVs are not present, or at least not functioning, at the

Table 3 Number of eyes with central retinal vein occlusion that showed changes of visual acuity in the follow up period with respect to the development of optociliary veins

\begin{tabular}{lll}
\hline & $\begin{array}{l}\text { Presence of } \\
\text { optociliary veins }\end{array}$ & $\begin{array}{l}\text { Absence of } \\
\text { optociliary veins }\end{array}$ \\
\hline Improved & 4 & 13 \\
Unchanged & 7 & 16 \\
Worsened & 13 & 26 \\
Total & 24 & 55 \\
\hline
\end{tabular}

onset of CRVO it is unlikely the ischaemia or oedema which develop soon after the onset of CRVO can be influenced by the frequent late development of OCVs. In particular, we found that most OCVs develop 1 year or more after the onset of CRVO and it seems improbable that after such a long time visual acuity could change depending on the appearance or absence of OCVs.

In addition, if OCVs cannot influence the development of retinal ischaemia, the opposite is also true - namely, that the development of OCVs does not depend on the presence or absence of ischaemia of the retina. The absence of correlation between OCVs and type of CRVO (non-ischaemic or ischaemic) shows that the development of these shunting vessels does not depend on the amount of vital retinal tissue. A further indication which confirms the independence of OCV development on the condition of retinal perfusion is given by the fact that there is no link between development of OCVs and importance of delayed filling of the central retinal vein. Therefore, the hypothesis that impairment of the outflow of the central retinal vein (which results in a delayed retinal venous phase in fluorescein angiography) can favour the development of alternative routes represented by OCVs is denied by our study.

Since OCVs have no prognostic value, the most important clinical relevance that can be attributed to them is the fact that they point to previous CRVO even in eyes where, because the condition dates back many years, every other sign of CRVO has disappeared. It is not known why OCVs appear in only a fraction of eyes with CRVO; perhaps they were present before the onset of CRVO, but not functioning.

1 Rodrigues MM, Savino PJ, Schatz NJ. Spheno-orbital meningioma with optociliary veins. Am $\mathcal{f}$ Ophthalmol 1976; 81: 666-70.

2 Spencer WH. Primary neoplasms of the optic nerve and its sheath. Clinical features and current concepts of patho-
genetic mechanisms. Trans Am Ophthalmol Soc 1972; 70: 490-528.

3 Salzmann M. Zur Anatomie der Angeborenen Sichel nach inner-unten. Graefes Arch Klin Ophthalmol 1893; 39: inner-un.

4 Hayreh SS. Blood supply of the optic nerve head and its role in optic atrophy, glaucoma, and oedema of the optic disc. Br F Ophthalmol 1969; 53: 721-48.

5 Klein BA. Spontaneous vascular repair. Arteriolar and venous cilioretinal communications. Am $\mathcal{F}$ Ophthalmol 1960; 50: 691-701

6 Vannas S, Raitta C. Anticoagulant treatment of retinal venous occlusion. Am F Ophthalmol 1966; 62: 874-84.

7 Priluck IA, Robertson DM, Hollenhorst RW. Long-term follow-up of occlusion of the central retinal vein in young adults. Am f Ophthalmol 1980: 90: 190-202.

8 De Crecchio G, Alfieri MC, Capocotta A, Sebastiani A. Vene optociliari e occlusioni venose retiniche. Boll Ocul 1991; 70 (Suppl 2): 325-30.

9 Dobree JH. Venous obstruction and neovascularisation at the disc in chronic glaucoma. Trans Ophthalmol Soc UK 1957; 77: 229-37.

10 Varma R, Spaeth GL, Katz LJ, Feldman RM. Collateral vessel formation inthe optic disc in glaucoma. Arch Ophthalmol 1987; 105: 1287 .

11 Frisén L, Hoyt WF, Tengroth BM. Optociliary veins, disc pallor and visual loss. A triad of signs indicating sphenoorbital meningioma. Acta Ophthalmol 1973; 51: 241-8

12 Hollenhorst RW, Hollenhorst RW Jr, McCarty CS. Visual prognosis of optic nerve sheath meningiomas producing shunt vessels on the optic disc. The Hoyt-Spencer syndrome. Trans Am Ophthalmol Soc 1977; 75: 141-63.

13 Imes RK, Schatz H, Hoyt WF, Monteiro MLR, Narahara M. Evolution of optociliary veins in optic nerve sheath meningioma. Arch Ophthalmol 1985; 103: 59-60.

14 Eggers HM, Sanders MD. Acquired optociliary shunt vessels in papilloedema. Br 7 Ophthalmol $1980 ; 64: 267-71$.

15 Perlmutter JC, Klingele TG, Hart WM Ir, Burde RM. 
Disappearing optociliary shunt vessels and pseudotumor cerebri. Am $\mathcal{Y}$ Ophthalmol 1980; 89: 703-7.

16 Anderson DP, Khalil M, Lorenzetti DWC, Saheb NE. Abnormal blood vessels on the optic disc. Can $\mathcal{F}$ Ophthalmo 1983; 18: 108-14.

17 Giuffrè G, Giuffrè V. Vene optociliari. Un segno di patologia della retina o del nervo ottico. Boll Ocul 1989; 68 (Suppl 1): 79-87.

18 Masuyama Y, Kodama Y, Matsuura Y, Sawada A, Harada K, Tsuchiya $T$. Clinical studies on the occurrence and the pathogenesis of optociliary veins. $\mathcal{f}$ Clin Neuro-ophthalmol 1990; 10: 1-8.

19 Hayreh SS, Hayreh MS. Hemi-central retinal vein occlusion. Pathogenesis, clinical features, and natural history. Arch Ophthalmol 1980; 98: 1600-9.

20 Wise GN, Dollery CT, Henkind P. The retinal circulation. New York: Harper \& Row, 1971.

21 Blinder KJ, Khan JA, Giangiacomo J, Ide $\mathrm{CH}$. Optociliary veins and visual prognosis after central retinal vein occlusion. Ann Ophthalmol 1989; 21: 192-7.

\section{History of ophthalmology}

\section{Thomas Wharton Jones, a nineteenth century ophthalmologist}

Many eminent ophthalmologists are worthy of eulogy, but although Wharton Jones isn't famous for any single thing today, his life touched on many of the most fascinating events of his times.

He studied medicine in Edinburgh, and worked with Knox, who was a talented speaker and 'enlarged his thinking greatly,' until the terrible scandal of Burke and Hare broke. For decades afterwards, 'burking' remained common slang for choking a person, which was exactly what Burke did to any creature that he thought might grace the slabs of Knox's laboratory. Wharton Jones, having been called as a witness in the extremely traumatic court case (public opinion was running murderously high), fled to practice in Glasgow, and never discussed the matter afterwards. Burke and Hare were, of course, hanged.

Wharton Jones later taught ophthalmology to London medical students, and wore the rather archaic dress of top hat and frock coat to do so. The students rudely and predictably named him 'Mummy Jones.' TH Huxley reports that he spoke in an 'outrageous Scottish accent,' but that his lectures were extremely well constructed, if one could only understand it! He wrote several textbooks, and his 'Catechism on Ophthalmology' used the principle that short questions and answers 'bring to mind forcibly the salient points of a subject.'

For example:

Question: 'What is the best local treatment for granular conjunctiva?'

Answer: 'Scarification every second day, and immediately thereafter the application of a strong salve.'

In 1848, his acquaintance Babbage showed him a contraption for viewing the inside of the eye. Jones describes it as a handheld mirror, with the silvering crudely scraped off at one point to form a hole through which one could look. He was only mildly impressed.

If he had realised its potential, then his name, with Babbage's, would have gone down in history in place of Helmholtz's. He would have been famous. Wharton Jones probably didn't realise this when Helmholtz first revealed his discovery, as he was appointed to the new professorship of ophthalmology at University College, and was too busy trying to catch his students calling him 'Mummy.' Three years later, he wrote a 'report' on the ophthalmoscope although, as Helmholtz's fame spread, he must have been kicking himself.

Sadly, hard times were ahead. Jones's private practice declined, as did the income from his books, and in the severe winter of 1881 , one $\mathrm{Mr}$ Tweedy was sent - through six foot deep snowdrifts - to ascertain why Jones had missed a Lancet staff meeting. Some concluded that at 73, he may have had an appointment with the Almighty, and idly composed bits of epitaph as Tweedy struggled on his mission. Arriving at Jones's house in George Street, he was horrified to find the eminent professor hunched over an empty grate wrapped in shawls, and knawing on an old piece of beefsteak and a crust. (Let this be a lesson to those of us who have not topped up our pension funds!) His colleagues swiftly persuaded Mr Gladstone to include him on the civil list, and he was saved from poverty and retired to the Isle of Wight. At this point he gave up practice completely, though couldn't resist treating his friend's tortoise at length, even after it bit him while he was putting in its eye drops.

It is hard to know whether his traumatic involvement with the Knox scandal and his 'missing'. the discovery of the ophthalmoscope soured him, especially as his own main invention (stereoscopic spectacles which he ground out of amber) never caught on. The fact that he continued working until his late sixties - his colleague Godlee met him again at this time and reports that he discussed with enthusiasm the merits of particular jams and the advantages of leather overshoes versus galoshes - suggests that it did not.

FIONA ROMAN

Currie AS. Robert Knox. In: Cope Z, ed. Sidelights on the history of medicine. London: Butterworth, 1957: 177-87.

Godlee RJ. Thomas Wharton Jones. Br f Ophthalmol 1921; 5: $97-$ $116,145-54$.

Merrington WR. University College Hospital - a history. London: Heinemann, 1976: 212-5.

Wharton Jones T. Obituary. Lancet 1891; i: 1256-8. 